\title{
Faults Detection and Isolation for energy management system in electric traction
}

\author{
Bejaoui Fatah ${ }^{1}$, Yahoui Hamed ${ }^{2}$, MechmecheChokri ${ }^{3}$,Hadjbraeik Naceur ${ }^{4}$ and Hammouri \\ Hassan $^{5}$ \\ ${ }^{1}$ Polytechnic school of Tunis (LSA):e-mail: fatah.bejaoui@isetn.rnu.tn \\ ${ }^{2}$ University Claude Bernard of Lyon,AMPERE, Lyon, France:e-mail: hamed.yahoui@univ-lyon1.fr \\ ${ }^{3}$ College of Applied Medical Sciences, Salman bin Abdul Aziz University, Al-kharj, Kingdom of Saudi \\ Arabiae-mail: mechdeux@yahoo.fr ${ }^{4}$ Polytechnic school of Tunis (LSA):e-mail: naceur.benhadj@ept.rnu.tn \\ ${ }^{5}$ UCBL, LAGEP, Lyon, France: e-mail: hammouri@lagep.univ-lyon1.fr
}

\begin{abstract}
This paper deals with the problem of diagnosis of faults in energy management for electric traction system .In fact, a bilinear model for the DC-DC (Boost and Buck/Boost) power converters is proposed. The analytical approach of residual generation using the observers with unknown inputs is reviewed, the computation of a bank of residual generators is exploited for fault detection and isolation, in the presence of disturbance. To illustrate the effectiveness of this method, simulations using Matlab/simulink are carried out.
\end{abstract}

Keywords-bilinear system, Buck boost, electric traction, residual.

\section{Introduction}

Nowadays monitoring industrial systems is a burgeoning field. A particularly important task in monitoring activity is the detection and location of the fault, which consists in determining whether or not there is a fault. Indeed, when the system is submitted to external disturbances, the ability to distinguish between the effect of a defect and that unmeasurable external disturbance in order to minimize false alarms, is therefore an essential property of a detection system[3][4]. Usually we have to estimate the state with unknown input observers and a robust residual generator for the external disturbances.

The suggested approach for fault detection and isolation in the energy management system for electric traction is based on state estimation and residual generation for bilinear system[8]. The residual generator with unknown inputs is designed to be sensitive to the faults and not affected by the disturbances.

Energy management in an electric traction system is provided by a fuel cell or a battery as main source and a supra-capacitor module as an auxiliary, we use two static converters(boost and buck/boost) to maintain the DC bus voltage constant [5]. The boost DC converter raises the battery voltage but the second has two modes: the first in case the electric power is converted from the load to the super capacitor pack (when braking), and the second which is the boost mode works otherwise (energy demand).

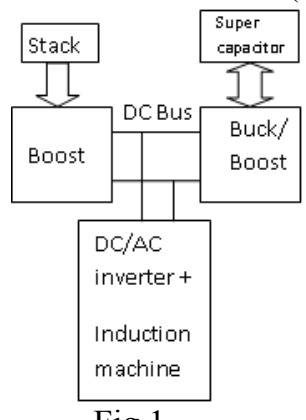

Fig 1

The diagnosis of this system is very important, indeed, whatever the aging mechanism considered.It has the effect of increasing the ESR (Equivalent Series Resistance) and reduce the total capacity value of the supra-capacitor. The non-reversible reactions appear to contribute to both phenomena simultaneously. The Monitoring of changes in the ESR and capacity value makes it possible to quantify the degree of ageing in use. The capacity reduction is principally reflected by a decrease in the energy that can be stored by the supra-capacity pack[1][6]. A significant decrease of this energy is a problem because the storage system may then not be able to meet the expectations of the specifications in energy terms. In turn, the increase in ESR is manifested by lower yields and greater voltage drops to extinction or establishment of the current. These increasing 
drops ohmic voltage make difficult the full charge / discharge system. Energy capacities can therefore also be diminished with the increase in ESR. In addition, the heating of the supra-capacitor is amplified with increased ESR. The thermal aspect is, therefore, more and more binding or risk having to increase the cooling time of the storage system during use[7].

This paper is organized as follows: an energy management system model is given in section 1 . Section 2 deals with the design of unknown inputs residual generation for bilinear system. In order to illustrate the effectiveness of the proposed method,a simulationis made in section 3. Finally, a conclusion is provided in section 4 .

\section{Energy management system model}

In this section, we present a global model for the energy management system which is formed by a one way DC-DC converter (the boost) and a bidirectional DC-DC converter (the buck/boost) presented by figure 1 .

$\mathrm{S}_{1}, \mathrm{~S}_{2}$ and $\mathrm{S}_{3}$ are respectively the command signal of transistor $T_{1}, T_{2}$ and $T_{3}$. The system operates in two modes.

First mode: The buck / boost operate as a buck mode.The equations of the two converters are given by:

$$
\begin{aligned}
& \frac{\mathrm{dI}_{\mathrm{L} 1}}{\mathrm{dt}}=\frac{\mathrm{U}_{\text {Bat }}}{\mathrm{L}_{1}}-\frac{\mathrm{V}_{\text {bus }}}{\mathrm{L}_{1}}+\frac{\mathrm{s}_{1}}{\mathrm{~L}_{1}} \mathrm{~V}_{\text {bus }} \\
& \frac{\mathrm{dI}_{\mathrm{L} 2}}{\mathrm{dt}}=\frac{\mathrm{V}_{\mathrm{sc}}}{\mathrm{L}_{2}}-\frac{\mathrm{R}_{\mathrm{sc}}}{\mathrm{L}_{2}} \mathrm{I}_{\mathrm{L} 2}-\frac{\mathrm{V}_{\text {bus }}}{\mathrm{L}_{2}} \mathrm{~s}_{3} \\
& \frac{\mathrm{dV}_{\text {bus }}}{\mathrm{dt}}=\frac{\mathrm{I}_{\mathrm{L} 1}}{\mathrm{C}_{\mathrm{f}}}\left(1-\mathrm{S}_{1}\right)+\frac{\mathrm{I}_{\mathrm{L} 2}}{\mathrm{C}_{\mathrm{f}}}\left(1-\mathrm{S}_{2}\right)-\frac{\mathrm{V}_{\text {bus }}}{\mathrm{R}_{\mathrm{ch}} \mathrm{C}_{\mathrm{f}}}
\end{aligned}
$$

Second mode:The buck/boost operate as a boost mode.The equations of the two converters are given by:

$$
\begin{aligned}
& \frac{\mathrm{dI}_{\mathrm{L} 1}}{\mathrm{dt}}=\frac{\mathrm{U}_{\text {Bat }}}{\mathrm{L}_{1}}-\frac{\mathrm{V}_{\text {bus }}}{\mathrm{L}_{1}}+\frac{\mathrm{s}_{1}}{\mathrm{~L}_{1}} \mathrm{~V}_{\text {bus }} \\
& \frac{\mathrm{dI}_{\mathrm{L} 2}}{\mathrm{dt}}=\frac{\mathrm{V}_{\mathrm{sc}}}{\mathrm{L}_{2}}-\frac{\mathrm{R}_{\mathrm{sc}}}{\mathrm{L}_{2}} \mathrm{I}_{\mathrm{L} 2}-\frac{\mathrm{V}_{\text {bus }}}{\mathrm{L}_{2}}\left(1-\mathrm{s}_{2}\right) \\
& \frac{\mathrm{dV}_{\text {bus }}}{\mathrm{dt}}=\frac{\mathrm{I}_{\mathrm{L} 1}}{\mathrm{C}_{\mathrm{f}}}\left(1-\mathrm{s}_{1}\right)+\frac{\mathrm{I}_{\mathrm{sc}}}{\mathrm{C}_{\mathrm{f}}}\left(1-\mathrm{s}_{2}\right)-\frac{\mathrm{V}_{\text {bus }}}{\mathrm{R}_{\mathrm{ch}} \mathrm{C}_{\mathrm{f}}}
\end{aligned}
$$

The two modes can be combined into one by making the following change of variables:

$$
\mathrm{u}_{4}=\left(1-\mathrm{s}_{2}\right) \mathrm{k}+\mathrm{s}_{3}(1-\mathrm{k}) \text { and } \mathrm{u}_{1}=\mathrm{s}_{1}
$$

Where $\mathrm{k}$ is a binary variable definedas:

$\left\{\begin{array}{lll}\mathrm{k}=0 & \text { buck } & \text { mode } \\ \mathrm{k}=1 & \text { boost } & \text { mode }\end{array}\right.$

which gives us: $\mathrm{k}=$ buck.$\overline{\text { Boost }}$
Both systems can be grouped into one. By combining the equations (1) with(2),(3) with(4) and(5) with(6), we obtain:

$$
\begin{aligned}
& \frac{\mathrm{dI}_{\mathrm{L} 1}}{\mathrm{dt}}=\frac{\mathrm{U}_{\text {Bat }}}{\mathrm{L}_{1}}-\frac{\mathrm{V}_{\text {bus }}}{\mathrm{L}_{1}}+\frac{\mathrm{u}_{1}}{\mathrm{~L}_{1}} \mathrm{~V}_{\text {bus }} \\
& \frac{\mathrm{dI}_{\mathrm{L} 2}}{\mathrm{dt}}=\frac{\mathrm{V}_{\mathrm{sc}}}{\mathrm{L}_{2}}-\frac{\mathrm{R}_{\mathrm{sc}}}{\mathrm{L}_{2}} \mathrm{I}_{\mathrm{L} 2}-\frac{\mathrm{V}_{\text {bus }}}{\mathrm{L}_{2}} \mathrm{u}_{4} \\
& \frac{\mathrm{dV}_{\text {bus }}}{\mathrm{dt}}=\frac{\mathrm{I}_{\mathrm{L} 1}}{\mathrm{C}_{\mathrm{f}}}\left(1-\mathrm{u}_{1}\right)+\frac{\mathrm{I}_{\mathrm{L} 2}}{\mathrm{C}_{\mathrm{f}}} \mathrm{u}_{4}-\frac{\mathrm{V}_{\text {bus }}}{\mathrm{R}_{\mathrm{ch}} \mathrm{C}_{\mathrm{f}}} \\
& \frac{\mathrm{dV} \mathrm{sc}}{\mathrm{dt}}=-\frac{\mathrm{i}_{\mathrm{L} 2}}{\mathrm{C}_{\mathrm{sc}}}
\end{aligned}
$$

The system of equations(8),(9) (10) and(11)can be put in matrix form. By taking the current in coil $\mathrm{L}_{1}$ $\mathrm{I}_{\mathrm{L} 1}$ and $\mathrm{I}_{\mathrm{L} 2}$ for $\mathrm{L}_{2}$, the $\mathrm{V}_{\mathrm{sc}}$ and the DC Bus voltage $\mathrm{V}_{\mathrm{Bus}}$ as output, we obtain a bilinear system with this form :

$$
\begin{aligned}
& \dot{x}(t)=A x(t)+B U(t)+\sum_{i=1}^{2} D u x(t)+D f(t)+F d(t) \\
& y(t)=C x(t)
\end{aligned}
$$

With $\quad \mathrm{x}(\mathrm{t}) \in \mathbb{R}^{\mathrm{n}}$ the input vector $\mathrm{u}^{\mathrm{T}}(\mathrm{t})=\left[\mathrm{u}_{1}(\mathrm{t}) \quad \mathrm{u}_{4}(\mathrm{t})\right] \in \mathbb{R}^{2}$, the output $\mathrm{y}(\mathrm{t}) \in \mathbb{R}^{3}$, the unknown input vector $d(t) \in \mathbb{R}^{a}$ the matrix $A, B, D_{i}$ and $\mathrm{C}$ are given by the following state variables:

$\mathrm{X}=\left[\begin{array}{c}\mathrm{I}_{\mathrm{L}} \\ \mathrm{I}_{\mathrm{L}} \\ \mathrm{V}_{\mathrm{bus}} \\ \mathrm{V}_{\mathrm{s}}\end{array}\right] \mathrm{A}=\left[\begin{array}{cccc}0 & 0 & -\frac{1}{\mathrm{~L}_{1}} & 0 \\ 0 & -\frac{\mathrm{R}_{s c}}{\mathrm{~L}_{2}} & 0 & \frac{1}{\mathrm{~L}_{2}} \\ \frac{1}{\mathrm{C}_{\mathrm{f}}} & 0 & -\frac{1}{\mathrm{R}_{\mathrm{ch}} \mathrm{C}_{\mathrm{f}}} & 0 \\ 0 & -\frac{1}{\mathrm{C}_{\mathrm{s}}} & 0 & 0\end{array}\right] \mathrm{B}=\left[\begin{array}{c}\frac{1}{\mathrm{~L}_{1}} \\ 0 \\ 0 \\ 0\end{array}\right]$

$\mathrm{D}_{1}=\left[\begin{array}{cccc}0 & 0 & \frac{1}{\mathrm{~L}_{1}} & 0 \\ 0 & 0 & 0 & 0 \\ -\frac{1}{\mathrm{C}_{\mathrm{r}}} & 0 & 0 & 0 \\ 0 & 0 & 0 & 0\end{array}\right] \mathrm{D}_{2}=\left[\begin{array}{cccc}0 & 0 & 0 & 0 \\ 0 & 0 & -\frac{1}{\mathrm{~L}_{2}} & 0 \\ 0 & \frac{1}{\mathrm{C}_{\mathrm{r}}} & 0 & 0 \\ 0 & 0 & 0 & 0\end{array}\right]$ 
$\mathrm{u}=\left[\begin{array}{l}\mathrm{u}_{1} \\ \mathrm{u}_{4}\end{array}\right] \mathrm{C}=\left[\begin{array}{llll}0 & 0 & 1 & 0 \\ 0 & 1 & 0 & 0 \\ 0 & 0 & 0 & 1\end{array}\right] \mathrm{F}=\left[\begin{array}{l}0 \\ 0 \\ 1 \\ 0\end{array}\right]$

\section{Unknown inputs bilinear system residual generation}

As for linear systems,defects may appear on the bilinear systems and affect the operation of the installation. The problem of the residual generation for the faults detection in bilinear systems can be treated according to the same criteria as for linear systems, namely,the residual sensitivity to defects identified and the robustness with respect to inputs.

We propose the residual generator for bilinear system defined by (12) and (13) as the following equations:

$$
\begin{aligned}
& \dot{\mathrm{z}}(\mathrm{t})=\mathrm{Hz}(\mathrm{t})+\mathrm{Ly}(\mathrm{t})+\mathrm{JU}(\mathrm{t})+\sum_{\mathrm{i}=1}^{2} \mathrm{~N}_{\mathrm{i}} \mathrm{u}_{\mathrm{i}} \mathrm{z}(\mathrm{t}) \\
& \mathrm{r}(\mathrm{t})=\mathrm{R}_{1} \mathrm{z}(\mathrm{t})+\mathrm{R}_{2} \mathrm{y}(\mathrm{t})
\end{aligned}
$$

Where $z(t)$ represents the state of the residual generator and $\mathrm{r}(\mathrm{t})$ represents the output signal called residual , $\mathrm{H}, \mathrm{N}_{\mathrm{i}}, \mathrm{J}, \mathrm{L}, \mathrm{R}_{1}$ and $\mathrm{R}_{2}$ are suitable matrices to be determined.

The system defined by equation (14) and (15) is a residual generator for the system (12), (13) if it satisfies the following three conditions for all $u(t)$ and $\mathrm{d}(\mathrm{t})[2]$.

$\mathrm{i} /$ for all $\mathrm{x}_{0}, \mathrm{z}_{0}$

$$
\lim _{t \rightarrow \infty} r(t)=0 \quad \text { if } f(t)=0, \forall t>0
$$

ii/ for an ( $\left(\begin{array}{lll}\mathrm{x} & \mathrm{n})\end{array}\right)$ dimensionnel matrix $\mathrm{T}$ and $z_{0}(t)=T x_{0}(t)$ :

$$
\text { if } f(t)=0 \text { then } z(t)=T x(t), \forall t>0 \text { iii/ }
$$

for $z_{0}(t)=T x_{0}(t)$

$$
\text { if } f(t) \neq 0 \text { then } r(t) \neq 0
$$

The condition (i) ensures that the residual of the observer is equal to zero regardless the presence of the input signal $\mathrm{u}(\mathrm{t})$ or the unknown disturbance $\mathrm{d}(\mathrm{t})$.

The second condition (ii) provides the state estimation of the system in the presence of disturbances.

Condition (iii) guarantees that the residual is sensitive to the fault vector $\mathrm{f}(\mathrm{t})$. The following figure shows the residual generator system:

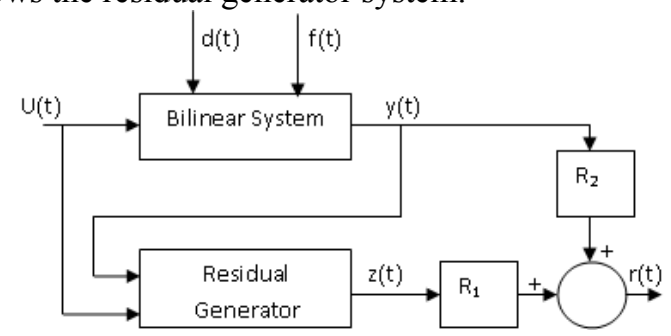

Fig 2:Residual generator scheme

\section{Unknown inputs residual generator design}

In this section, we give the procedure design of residual generator particularly the condition of stability and the algorithm for matrix determination. In fact, we define the estimation error as

$$
\mathrm{e}(\mathrm{t})=\mathrm{z}(\mathrm{t})-\mathrm{Tx}(\mathrm{t}) \text { from (14) and (15) }
$$

The time derivative of the error is as follows: $\dot{\mathrm{e}}(\mathrm{t})=\mathrm{He}(\mathrm{t})+(\mathrm{HT}-\mathrm{TA}+\mathrm{LC}) \mathrm{x}(\mathrm{t})+(\mathrm{J}-\mathrm{TB}) \mathrm{U}(\mathrm{t})$

$$
-\mathrm{TFd}(\mathrm{t})+\sum_{\mathrm{j}=1}^{2}\left(\mathrm{~N}_{\mathrm{j}} \mathrm{C}-\mathrm{TD}_{\mathrm{j}}\right) \mathrm{u}_{\mathrm{j}}(\mathrm{t})-\mathrm{TRf}(\mathrm{t})
$$

With

$$
\begin{aligned}
r(t) & =R_{1}[e(t)+T x(t)]+R_{2} y(t) \\
& =R_{1} e(t)+\left[R_{1} T+R_{2} C\right] x(t)
\end{aligned}
$$

To obtain $r(t)=R_{1} e(t)$ the following equation must be fulfilled:

$$
\mathrm{R}_{1} \mathrm{~T}+\mathrm{R}_{2} \mathrm{C}=0
$$

And then the estimation error can be written such that[12]:

$$
\begin{aligned}
& \dot{\mathrm{e}}(\mathrm{t})=\mathrm{He}(\mathrm{t}) \\
& \text { if the following relation holds } \\
& \mathrm{J}=\mathrm{TB} \\
& \mathrm{TF}=0 \\
& \mathrm{HT}+\mathrm{LC}-\mathrm{TA}=0 \\
& \mathrm{~N}_{\mathrm{i}} \mathrm{C}-\mathrm{TD}_{\mathrm{i}}=0 \quad \text { with } \mathrm{i}=1,2
\end{aligned}
$$

The design of the unknown inputs residual generator (14) and (15) is reduced to the determination of the matrix $\mathrm{H}, \mathrm{N}_{\mathrm{i}}, \mathrm{L}, \mathrm{J}, \mathrm{R}_{1}$ and $\mathrm{R}_{2}$ so that the dynamic error which can be written as (16) is stable and equations (17),(18),(19) and (20) are satisfied.

To determine $\mathrm{N}_{\mathrm{i}}$ the equations (21) can be rewritten in the following compact

form:

$\overline{\mathrm{N}} \overline{\mathrm{C}}-\mathrm{T} \overline{\mathrm{D}}=0$

Where $\overline{\mathrm{N}}, \overline{\mathrm{C}}$, and $\overline{\mathrm{D}}$ are given by :

$\overline{\mathrm{N}}=\left[\begin{array}{ll}\mathrm{N}_{1} & \mathrm{~N}_{2}\end{array}\right], \overline{\mathrm{C}}=\left[\begin{array}{ll}\mathrm{C} & 0 \\ 0 & \mathrm{C}\end{array}\right]$, and $\overline{\mathrm{D}}=\left[\begin{array}{ll}\mathrm{D}_{1} & \mathrm{D}_{2}\end{array}\right]$ by multiplying equation (22) with $\left[\overline{\mathrm{C}}^{+} \operatorname{ker}(\overline{\mathrm{C}})\right]$ we obtain:

$\overline{\mathrm{N}} \overline{\mathrm{C}}\left[\overline{\mathrm{C}}^{+} \quad \operatorname{ker}(\overline{\mathrm{C}})\right]-\mathrm{T} \overline{\mathrm{D}}\left[\overline{\mathrm{C}}^{+} \quad \operatorname{ker}(\overline{\mathrm{C}})\right]=\left[\begin{array}{ll}0 & 0\end{array}\right]$ witch equivalent to :

$\left\{\begin{array}{l}\overline{\mathrm{N}}=\mathrm{T} \overline{\mathrm{D}} \overline{\mathrm{C}}^{+} \\ \mathrm{T} \overline{\mathrm{D}} \operatorname{ker}(\overline{\mathrm{C}})=0\end{array}\right.$

Equation (19) combined with (24) one obtains :

$\mathrm{T}[\mathrm{F} \quad \overline{\mathrm{D}} \operatorname{ker}(\overline{\mathrm{C}})]=0$ This is written as

$\mathrm{T} \Phi=0$

with $\Phi=\left[\begin{array}{ll}\mathrm{F} & \overline{\mathrm{D}} \operatorname{ker}(\overline{\mathrm{C}})]\end{array}\right.$ 
To determine the matrix $R_{1}$ and $R_{2}$ we assume that the matrix $\Phi$ given by (26) is of full column rank. Then, there exists a matrix $\Phi_{\mathrm{c}}$ that $\left[\begin{array}{ll}\Phi & \Phi_{\mathrm{c}}\end{array}\right]$ is nonsingular. By multiplying the equality (16) by $\left[\Phi \Phi_{\mathrm{c}}\right]$ one obtains:

$\left[\left(\mathrm{R}_{1} \mathrm{~T}+\mathrm{R}_{2} \mathrm{C}\right)\right]\left[\begin{array}{ll}\phi & \phi_{\mathrm{c}}\end{array}\right]=0$

Which is equivalent to:

$$
\begin{aligned}
& \mathrm{R}_{1} \mathrm{~T} \phi+\mathrm{R}_{2} \mathrm{C} \phi=0 \\
& \mathrm{R}_{1} \mathrm{~T} \phi_{\mathrm{c}}+\mathrm{R}_{2} \mathrm{C} \phi_{\mathrm{c}}=0
\end{aligned}
$$

Taking condition (25) the equation (26) becomes:

$\mathrm{R}_{2} \mathrm{C} \phi=0$ This admits a parameterized solution:

$\mathrm{R}_{2}=\mathrm{V}\left[\mathrm{Ip}-(\mathrm{C} \phi)(\mathrm{C} \phi)^{+}\right], \mathrm{V} \in \mathbb{R}^{1 \times p}$

If and only if

$$
\operatorname{rank}(\mathrm{C} \phi)=\operatorname{rank}(\phi)
$$

By substituting the equation (29) into (27), one obtains:

$$
\mathrm{R}_{1} \mathrm{~T} \phi_{\mathrm{c}}+\mathrm{V}\left[\mathrm{I}_{\mathrm{p}}-(\mathrm{C} \phi)(\mathrm{C} \phi)^{+}\right] \mathrm{C} \phi_{\mathrm{c}}=0
$$

Which gives us:

$$
\mathrm{R}_{1} \mathrm{~T}+\mathrm{VC}\left[\mathrm{I}_{\mathrm{p}}-\phi(\mathrm{C} \phi)^{+} \mathrm{C}\right]=0
$$

To satisfy equation (30), we choose the matrix $R_{1}$ and $\mathrm{T}$ as following:

$$
\begin{aligned}
& \mathrm{R}_{1}=-\mathrm{VC} \\
& \mathrm{T}=\mathrm{I}_{\mathrm{p}}-\phi(\mathrm{C} \phi)^{+} \mathrm{C}
\end{aligned}
$$

Now, we can determine the $\mathrm{J}$ matrix by substituting the matrix $\mathrm{T}$ in equation (18).By replacing the expression of $\mathrm{T}$ into the equation (20), one obtains:

$$
\mathrm{H}\left[\mathrm{I}_{\mathrm{p}}-\phi(\mathrm{C} \phi)^{+} \mathrm{C}\right]=\mathrm{TA}-\mathrm{LC}
$$

Which is equivalent to :

$$
\mathrm{H}=\mathrm{TA}-\left[\mathrm{L}-\mathrm{H} \phi(\mathrm{C} \phi)^{+}\right] \mathrm{C}
$$

We pose: $\mathrm{K}=\mathrm{L}-\mathrm{H} \phi(\mathrm{C} \phi)^{+}$

Expression (34) gives us $\mathrm{H}=\mathrm{TA}-\mathrm{KC}$

The determination of the gain matrix is done by pole placement which gives us: $\mathrm{L}=\mathrm{K}+\mathrm{H} \phi(\mathrm{C} \phi)^{+}$
Existence conditions:

Theorem:The system defined by equation (12) and (13) is a residual generator of the system defined by (14) and (15) if and only if the two conditions are satisfied:

$$
\begin{aligned}
& \operatorname{rank}\left[\begin{array}{cc}
\mathrm{sI}_{\mathrm{n}}-\mathrm{A} & \Phi \\
\mathrm{C} & 0
\end{array}\right]=\mathrm{n}+\operatorname{rank} \Phi \quad \forall \mathrm{s} \in \mathbb{C}^{+} \\
& \operatorname{rank}(\mathrm{C} \Phi)=\operatorname{rank}(\Phi)
\end{aligned}
$$

Condition (36) must be verified to resolve equation (25)[10][11]. Condition (35) is related to the stability of the observer [9][13].

\section{Defaults isolation}

To locate and isolate the defaults we opt for the bank of observer's method with unknown inputs described by the following figure:

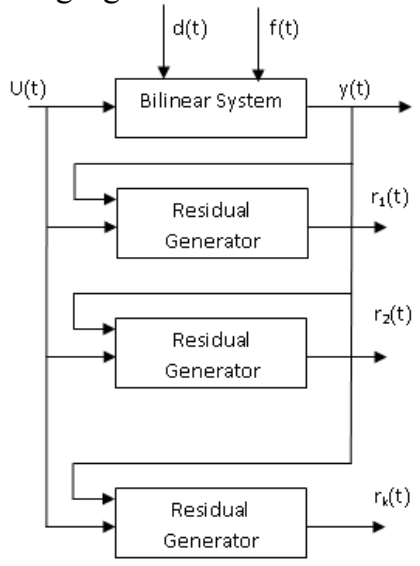

Fig 3:Bank of observer scheme

Suppose our system is affected by k different defects $d_{i}(t)(i=1 . . k)$ So the bank of observers should be able to generate sufficient residues to detect and isolate the occurrence of each coordinate of the vector of defects $d_{i}(t)$.In fact, the simplest solution is to synthesize $\mathrm{k}$ generators residues unknown input for the ith residue noted $r_{i}(t)$, is nonzero if $d_{i}(t) \neq 0$.

\section{Numeric application}

We take the following values: $\mathrm{L}_{1}=0.330 \mathrm{H} ; \mathrm{L}_{2}=0.330 \mathrm{H} ; \mathrm{C}_{\mathrm{F}}=0.0008 \mathrm{~F} ; \mathrm{R}_{\mathrm{sc}}=0.001 \Omega$;

$\mathrm{R}_{\mathrm{ch}}=100 \Omega ; \mathrm{C}_{\mathrm{sc}}=70 \mathrm{~F}$; which gives us for the observer the following matrices:

$\mathrm{E}=\left[\begin{array}{ccc}0 & 1.0 & 0 \\ 0.5 & 0 & 0.5 \\ 0.5 & 0 & 0.5 \\ 0.5 & 0 & 0.5\end{array}\right] \Phi=\left[\begin{array}{llll}0 & 1 & 0 & 0 \\ 1 & 0 & 0 & 0 \\ 1 & 0 & 0 & 0 \\ 1 & 0 & 0 & 0\end{array}\right]$

$\mathrm{H}=\left[\begin{array}{cccc}-7.8509 & 10.2905 & 1.5969 & 0 \\ 10.4041 & -38.0234 & 11.1179 & 1.5152 \\ 1.42271 & 11.3776 & -19.6106 & -1.5152 \\ 1.8920 & -8.3836 & 4.9739 & -1.5152\end{array}\right]$ 


$$
\begin{aligned}
& \mathrm{E} 1=\left[\begin{array}{ccc}
0 & 0 & 0 \\
0 & 0 & 1.0 \\
1.0 & 0 & -0.0 \\
0 & 0 & 1.0
\end{array}\right] \Phi 1=\left[\begin{array}{llll}
0 & 0 & 0 & 0 \\
1 & 1 & 0 & 0 \\
1 & 0 & 0 & 0 \\
1 & 1 & 0 & 0
\end{array}\right] \\
& \mathrm{H} 1=\left[\begin{array}{cccc}
0 & 0 & -0 & 0 \\
-0 & -0 & 0 & 0 \\
-0 & 0 & -0 & 0 \\
-0 & 3.7803 & 0 & -0
\end{array}\right] \\
& \mathrm{K}=\left[\begin{array}{cccc}
-1.5969 & -4.8679 & 13.3606 & 1.7769 \\
7.8509 & -635.4041 & 623.5729 & -626.8920 \\
-10.2905 & 38.0219 & -11.3761 & 8.3709
\end{array}\right]
\end{aligned}
$$

\section{Simulation}

The result of the simulation is taken by injecting a default $\mathrm{d}_{1}(\mathrm{t})$ which occurs at time $\mathrm{t}=4 \mathrm{~s}$ to $\mathrm{t}=4.5 \mathrm{~s}$ fig 3 . In this case the second static converter operates in buck mode.

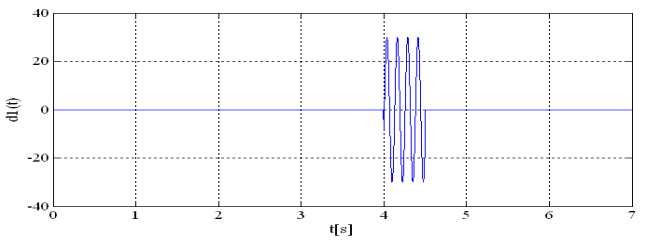

fig4: fault $d_{1}(t)$

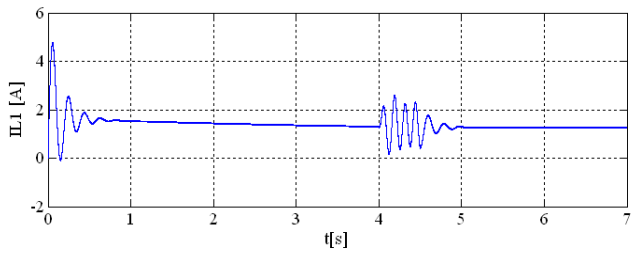

Fig 5: The current shape in the $\mathrm{L}_{1}$ coil after the default

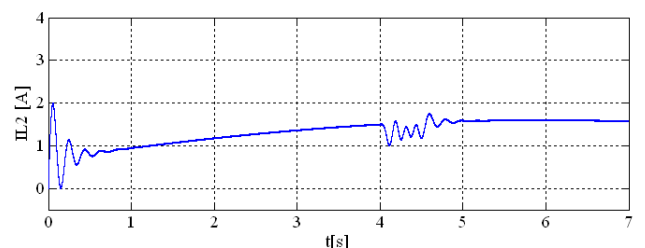

Fig 6: The current shape in the $\mathrm{L}_{2}$ coil after the default

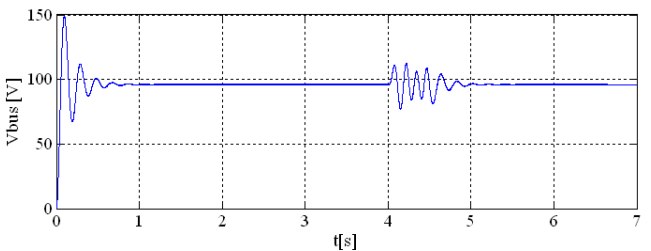

Fig 7: The $\mathrm{V}_{\text {bus }} \mathrm{DC}$ voltage after the default

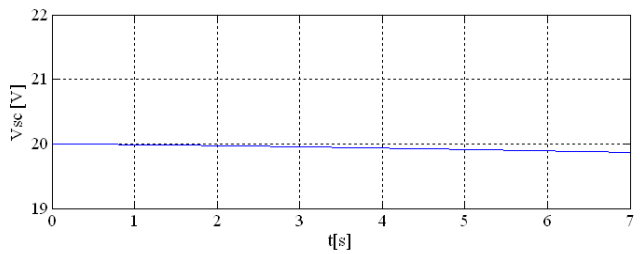

Fig $8: \mathrm{V}_{\mathrm{sc}}$ voltage in super capacitor after the default

The residual is almost zero as long as the time simulation runs.The magnitude increases considerably when the fault occurs at time $\mathrm{t}=4 \mathrm{~s}$ to $\mathrm{t}=4.5 \mathrm{~s}$ (fig 9)

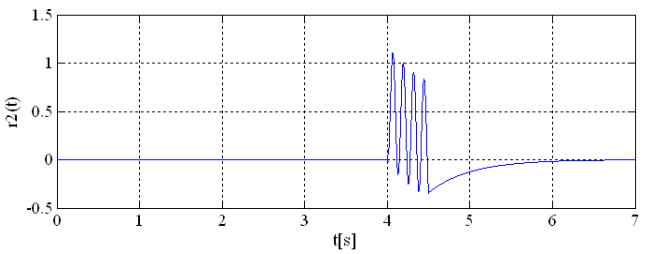

Fig 9:Residual generation

Simulation result for the isolation of the default after addition of two faults in the input: in this case we have design two observers, the first detects the first fault $d_{1}(t)$, considers the second fault as unknown input and generates the residual $r_{1}(t)$. The second observer detects the second fault $\mathrm{d}_{2}(\mathrm{t})$,considers the first fault as unknown input and generates the residual $\mathrm{r}_{2}(\mathrm{t})$.

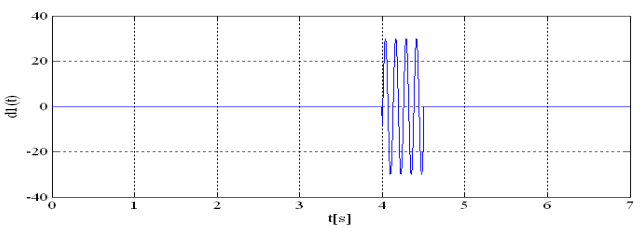

Fig 10 : fault $\mathrm{d}_{1}(\mathrm{t})$

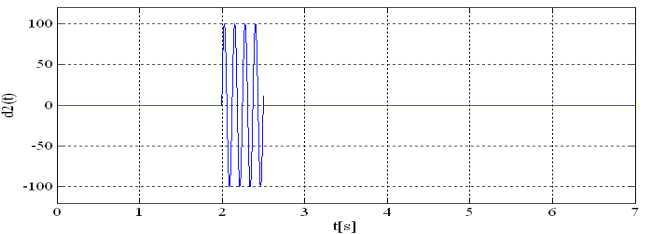

Fig 11 : fault $\mathrm{d}_{2}(\mathrm{t})$

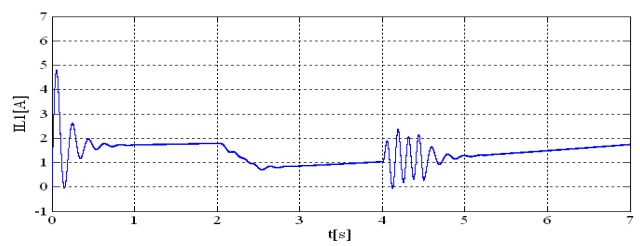

Fig 12: The current shape in the $\mathrm{L}_{1}$ coil after the default 


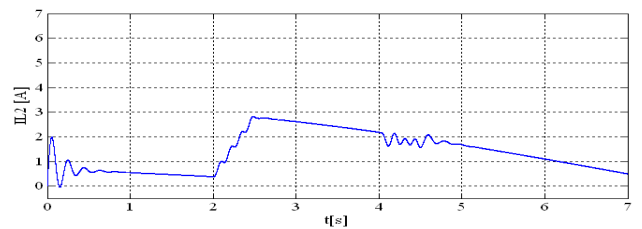

Fig 13: The current shape in the $\mathrm{L}_{2}$ coil after the default

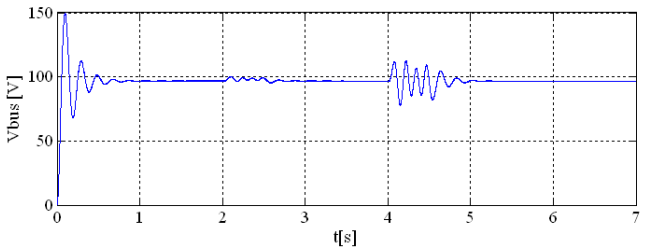

Fig 14: The $\mathrm{V}_{\text {bus }}$ DC voltage after the default

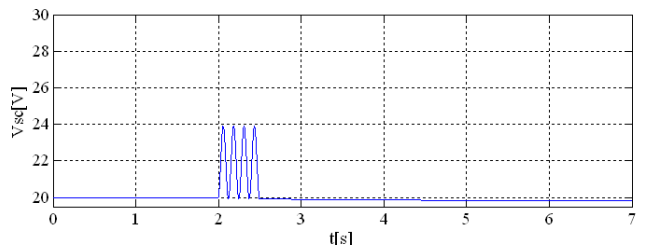

Fig $15: \mathrm{V}_{\mathrm{sc}}$ voltage in super capacitor after the default

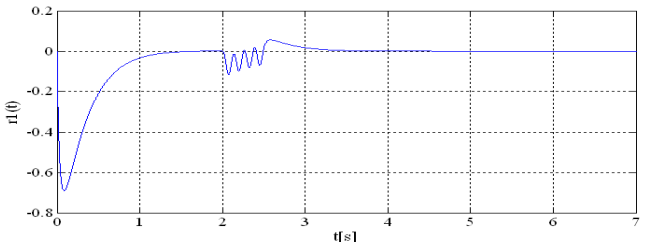

Fig 16:The residual $r_{1}(t)$ sensible to the first fault

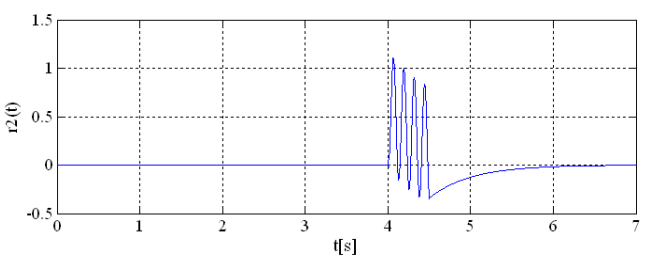

Fig 17:The residual $r_{2}(t)$ sensible to the second fault

\section{Conclusion}

This paper was devoted to the faults detection and isolation of energy management system for electric traction. We have proposed a method for fault detection based on bilinear unknown inputs observers. By using a bank of observers, a fault detection and isolation technique is validated. Finally a simulation and numeric application, given the results obtained, shows the validity of the approachused.

\section{References}

[1] S. Caux, J. Lachaize,M. Fadel,P. Shott,L. Nicod ,"Modelling and control of Fuel Cell System and Storage Elements in Transport Applications", Journal of Process Control , 2005 ,Vol 15 pp 481-491.

[2] M. Zasadzinski,H. Rafaralahy,C . Mechmeche,M. Darouach, "On Distriburance Decoupled Observers for a Class of Bilinear Systems", Journal of Dynamic Systems,Mesurement,andControl,Septembre 1998, vol 120 pp 371,377 .

[3] H.Dallagi, C.Mechmeche, S.Nejim "The modeling of ship electric propulsion system for faults detection and isolation", $4^{\text {th }}$ international multi-conference on system, signals and devices SSD 2007 , vol II

[4] H.Dallagi, C.Mechmeche, N. Benhadjbraik "Fault detection and isolation of ship electric propulsion sustem using residual generator", $8^{\text {th }}$ international multi-conference on system, signals and devices SSD 2011 .

[5] N. Gonzalez-Fonseca,J. de Leon-Morales,J .LeyvaRamos,"Observer-Based Controller for Switch-Mode DC-DC Converters" , 44 ${ }^{\text {th }}$ IEEE Conference on Decision and Control,and the European Control Conference 2005 , Seville, Spain , December 12-15, 2005.

[6] M.B. Camara, H. Gualous, F. Gustin, A. Berthon," Design and New Control of DC/DC Converters to share energy between Super capacitors and Batteries in Hybrid Vehicle", IEEE Trans. on Vehicular Technology, ISSN 0018-9545, Vol.57.

[7] M B. Camara , H. Gualous, F. Gustin, A. Berthon, "Experimental study Buck-Boost converters with polynomial Control strategy for Hybrid Vehicles Applications, International Review of Electrical Engineering" (IREE), ISSN 1827-6660,Vol.2, No.4, Pages : 601-611, July-August 2007.

[8] Micah Ortúzar, Juan Dixon . Jorge Moreno "Design, Construction and Performance of a Buck-Boost Converter for an Ultracapacitor-Based Auxiliary Energy System for Electric Vehicles”, 2003 IEEE.

[9] Funahashi Y., "Stable state estimator for bilinear systems,"Int.J.Control, vol.29, No. 2, pp 181-188, 1979.

[10] J. C. Mayo-Maldonado, R. Salas-Cabrera, J. de-LeonMorales, E. N. Salas-Cabrera,R. Castillo-Gutierrez, J. E. Martinez-Bernal, D. Soto- Monterrubio «On the Output Current Estimation of a DC-DC Multiplier Converter ", the World Congress on Engineering and Computer Science 2011 Vol I ,WCECS , san Francisco, USA.

[11] Grasselli, O.M.,andIsidori,A., "An Existence theorem for observers of bilinear systems," IEEETrans. Autom. Control, vol.AC-26, pp 1299-1300, Jun. 1981.

[12] Darouach M., Zasadzinski M. and Xu S. J., "Full order observer for linear systems with unknown inputs", IEEE Transaction on Automatic control, vol 39, No. 3, pp 606-609, 1994.

[13] Besançon G. and Hammouri H., "On uniforme Observation of nonuniformely observable sys-tems", System and Control Letters, Vol.29, pp 9-19, 1996. 